\title{
Yeast as a model system to study metabolic impact of selenium compounds
}

\author{
Enrique Herrero ${ }^{1, *}$ and Ralf Erik Wellinger ${ }^{2}$ \\ ${ }^{1}$ Departament de Ciències Mèdiques Bàsiques, Universitat de Lleida, IRBLleida, Rovira Roure 80, 25198 Lleida, Spain. \\ ${ }^{2}$ Centro Andaluz de Biología Molecular y Medicina Regenerativa (CABIMER), Universidad de Sevilla, 41092 Sevilla, Spain. \\ * Corresponding author: Enrique Herrero, Departament de Ciències Mèdiques Bàsiques, Universitat de Lleida, IRBLleida, Edifici Bio- \\ medicina I, Rovira Roure 80; 25198-Lleida, Spain; Tel: +34 973702266; E-mail: enric.herrero@cmb.udl.cat
}

\begin{abstract}
Inorganic Se forms such as selenate or selenite (the two more abundant forms in nature) can be toxic in Saccharomyces cerevisiae cells, which constitute an adequate model to study such toxicity at the molecular level and the functions participating in protection against Se compounds. Those Se forms enter the yeast cell through other oxyanion transporters. Once inside the cell, inorganic Se forms may be converted into selenide through a reductive pathway that in physiological conditions involves reduced glutathione with its consequent oxidation into diglutathione and alteration of the cellular redox buffering capacity. Selenide can subsequently be converted by molecular oxygen into elemental Se, with production of superoxide anions and other reactive oxygen species. Overall, these events result in DNA damage and dose-dependent reversible or irreversible protein oxidation, although additional oxidation of other cellular macromolecules cannot be discarded. Stress-adaptation pathways are essential for efficient Se detoxification, while activation of DNA damage checkpoint and repair pathways protects against Se-mediated genotoxicity. We propose that yeast may be used to improve our knowledge on the impact of Se on metal homeostasis, the identification of Setargets at the DNA and protein levels, and to gain more insights into the mechanism of Se-mediated apoptosis.
\end{abstract}

doi: $10.15698 /$ mic2015.05.200 Received originally: 30.01 .2015 ; in revised form: 24.02.2015, Accepted 02.03.2015 Published 08.04.2015

Keywords: selenium, yeast, DNA damage, oxidative stress, mitochondrial function, signal transduction.

\section{Abbreviations:}

GLR1 - glutathione reductase, GSH - reduced glutathione, GSSG - oxidized glutathione, MPT - mitochondrial permeability transition, ROS - reactive oxygen species.

\section{INTRODUCTION}

Selenium (Se) is an element that shares characteristics of both metals and nonmetals, being therefore considered as a metaloid. Similarly to sulfur, Se has different oxidation states ranging from $+\mathrm{VI}$ to $-\mathrm{II}$. In the external environments found on earth it is present in low amounts, generally as selenate $\mathrm{Se}(+\mathrm{VI})$ or selenite $\mathrm{Se}(+\mathrm{IV})$, although these amounts vary considerably depending on the geographical areas [1]. Se is an essential nutritional supplement in the human diet, and intake doses between 30 and $55 \mu \mathrm{g}$ per day are recommended, while doses lower than $10 \mu \mathrm{g}$ per day can be detrimental for human health [2]. Thus, Se deficiency has been associated with increased risk of mortality, poor immune function and cognitive decline. This nutritional requirement is explained by the fact that Se (in the form of selenocysteine) is a component of about 25 human selenoproteins, among them several glutathione peroxidases and thioredoxin reductases [3]. These two enzyme activities participate in the defense against oxidants, with a selenocysteine residue as part of the enzyme active site [4].

In addition to their known role in combating various forms of degenerative diseases, the impact of organoselenium compounds in cancer chemoprevention has been studied, and thus, doses up to 200-300 $\mu$ g per day are proposed to protect against diverse types of cancer (prostate, colorectal and lung) on the basis of the Se antioxidant role [5-9]. However, epidemiological analyses have associated high Se levels in the serum with cardiovascular disease, amyotrophic lateral sclerosis and diabetes as well as with carcinogenesis [10-14]. Taken together, the narrow range between beneficial and toxic Se concentrations poses caution on the use of Se-enriched supplements in animal and human nutrition, and makes it also difficult to study Se effects in human (or other animal) cell models. While selenoproteins are found in bacteria, archaea, some algae and protozoa, vertebrates and invertebrates, they have not been reported in fungi and plants $[15,16]$. Be- 
cause Saccharomyces cerevisiae has no metabolic need for $\mathrm{Se}$, it is an adequate organism to study the toxic effects of Se forms on cell functions [14]. In recent years, diverse studies (some of them including -omic approaches) have investigated the toxicity of inorganic Se forms on yeast cells, at the molecular and/or physiological levels. Here, we provide an overview on the current knowledge on Se uptake, the impact of toxic Se on genome stability and other functions, and the activation of intracellular signaling events leading to Se detoxification and tolerance in yeast cells.

\section{Se COMPOUNDS IN NATURE}

In the environment, Se is found in four oxidation states, elemental selenium $\mathrm{Se}(0)$ and soluble selenate $\mathrm{Se}(+\mathrm{VI})$, selenite $\mathrm{Se}(+\mathrm{IV})$, and selenide $\mathrm{Se}(-\mathrm{II})$ (see Fig. 1). $\mathrm{Se}(-\mathrm{II})$ is found as volatile, methylated species or as organoselenium typically in the form of proteins containing the amino acids selenocysteine and selenomethionine [17]. Anaerobic microorganisms such as Thauera selenatis can respire toxic oxyanions of Se, namely selenate and selenite [18], and reduce them to insoluble $\mathrm{Se}(0)$ as well as hydrogen selenide [19]. These microorganisms either use selenate or selenite as their respiratory electron acceptor for the oxidation of organic carbon substrates like lactate or acetate to carbon dioxide. Thereby, these toxicants can be effectively removed from solution via a microorganismmediated precipitation to non-toxic $\mathrm{Se}(0)$ [20]. Thus, the common link is that Se specification in nature is strongly dependent on microbial activity [21, 22]. The formation of $\mathrm{Se}(0)$ nanoparticles (20-300 $\mathrm{nm}$ in diameter) by seleniumrespiring bacteria and yeast is a phenomenon that deserves special mention $[19,23]$. They occur outside the cell envelope, eventually slough off the cell surface and get released into the medium. When harvested and cleansed of their cellular parents, they were found to have curious electro-optical properties, making them candidates for further studies with "nanotechnological" applications [24].

Inorganic Se compounds can also be metabolized inside the cell through a reductive pathway from selenate to selenide (Fig. 1). This process involves reduced glutathione (GSH) with the consequent formation of oxidized glutathione (GSSG) and reactive oxygen species (ROS) [25-27]. Selenide is also the intermediate for the formation of selenocysteine, from which selenomethionine can then be formed in organisms with a functional transsulfuration pathway. Several metabolomics studies [28-30] have shown that a plethora of additional organoselenium compounds accumulate in yeast cells supplemented with selenate, selenite or selenomethionine, in addition to demonstrating that selenocysteine can also be formed from selenomethionine.

\section{UPTAKE OF INORGANIC Se FORMS}

Specific transporters for uptake of inorganic Se compounds still need to be characterized in eukaryotic cells. In S. cerevisiae, selenate probably enters through the high affinity sulfate permeases Sul1 and Sul2. Thus, a double mutant lacking both transporters is hyperresistant to selenate as well as to chromate [31], suggesting that both oxyanions adventitiously employ the sulfate transporters to enter into the yeast cells. Consistent with this observation, later experiments demonstrated that chromate and sulfate compete with each other to enter into the cells [32], although similar experiments have not been done with selenate. Also, heterologous expression of a plant sulfate transporter, SHST1, in S. cerevisiae sul1 mutant cells allows increased uptake of molybdate, while increasing molyb-

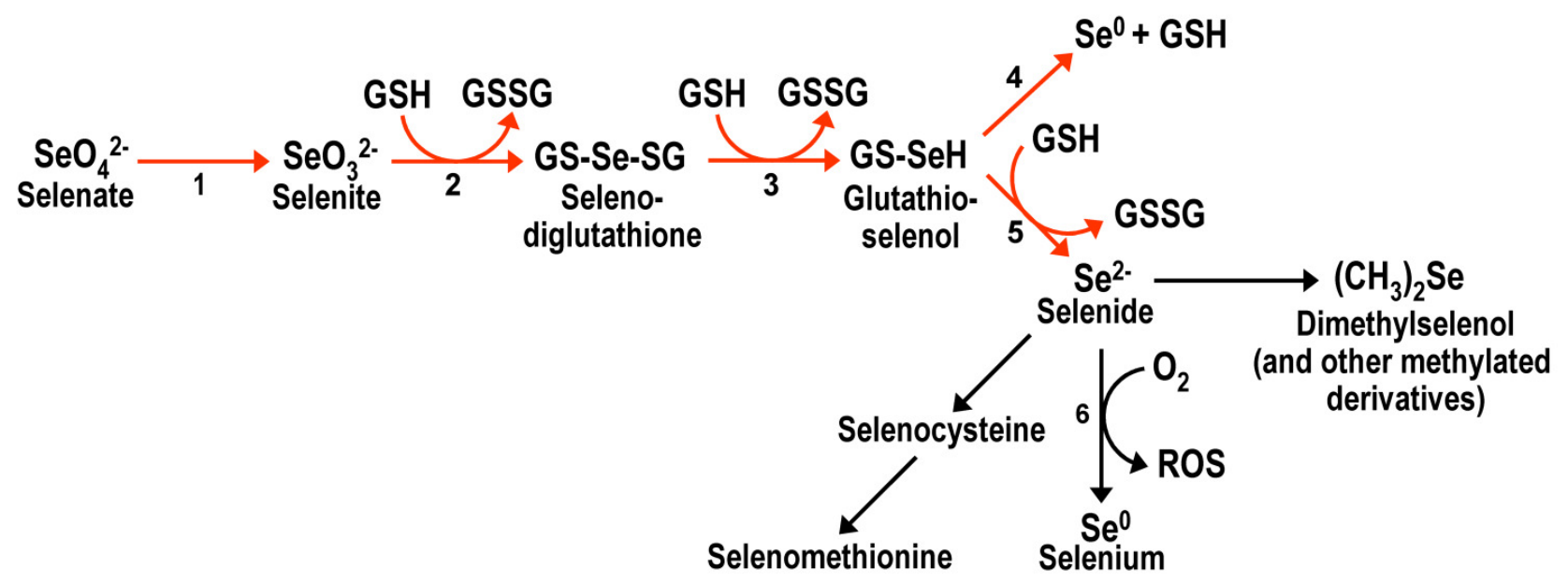

FIGURE 1: Scheme for the metabolic reduction of inorganic selenium forms, and their conversion into organic forms. Reductive reactions are indicated with red arrows. Arrow 1 corresponds to the reactions involving ATP sulfurylase and other enzymes that take part in the initial steps of the sulfate assimilation pathway. Reactions 2 to 5 are non-enzymatic and result in the net conversion of reduced glutathione (GSH) into oxidized glutathione (GSSG). Reaction 6 is also non-enzymatic and results in the formation of diverse reactive oxygen species. Adapted from [25], [26], [27] and [36]. 
date concentration in the medium interferes with sulfate entry [33], suggesting that sulfate and molybdate share the same transport system. Therefore, the Sul1/Sul2 transport system seems to be used by diverse oxyanions (+VI) for entry into $S$. cerevisiae.

Initial work on the kinetics of selenite uptake indicated the existence of both a high affinity and a low affinity transport system operating at different selenite concentrations [34]. In parallel, another study pointed to the interaction between selenite and ortophosphate assimilation [35]. On the other hand, reducing molecules present in the growth medium such as glutathione or other thiols would reduce selenite to hydrogen selenide, which would then be internalized into the cells to cause toxicity [36]. However, there is no evidence of the existence of selenide transporters in S. cerevisiae or other eukaryotic organisms.

A detailed study by Lazard et al. [37] confirmed that selenite employs phosphate transporters to enter into yeast cells. Two different transport systems mediate ortophosphate uptake in S. cerevisiae [38, 39]. The high affinity phosphate transport system is composed of the Pho84 and Pho89 transporters and functions at both low and high phosphate concentrations. Expression of the PHO84 and $\mathrm{PHO} 89$ genes is upregulated at low phosphate concentration depending on the $\mathrm{PHO}$ signal transduction pathway, with the Pho4 transcription factor as effector of the pathway [40]. Pho84 transporter operates preferentially at neutral and acidic $\mathrm{pH}$, while Pho89 is functional at alkaline $\mathrm{pH}$ [41]. The low affinity transport system operates at high phosphate concentrations, is composed by Pho87, Pho90 and Pho91, and is post-transcriptionally downregulated at low phosphate conditions by Spl2, a member of the $\mathrm{PHO}$ regulon $[38,39]$. Depending on phosphate levels in the medium, selenite enters the yeast cell through Pho84 or Pho87/Pho90/Pho91 [37]. At very low phosphate levels (up to $0.1 \mathrm{mM}$ ) selenite enters efficiently through Pho84 and is highly toxic. Given that Pho84 displays a much higher affinity for phosphate than for selenite, while the phosphate low affinity system is considerably more unspecific, phosphate favorably competes with selenite at moderately higher phosphate levels (up to $0.4 \mathrm{mM}$ ) and selenite becomes less toxic. At still higher phosphate levels selenite enters through the less discriminatory low affinity system and becomes highly toxic again [37]. Interestingly, arsenate also can adventitiously enter $S$. cerevisiae cells through the Pho84 and phosphate low affinity transporters [42, 43], indicating that phosphate transporters contribute to the toxic uptake of a wide range of compounds [44].

Glucose was the only carbon/energy source used in the studies described above but apparently, the Jen 1 transporter acts as an alternative selenite and arsenite transporter in the presence of other carbon sources [45]. The JEN1 gene codes for a plasma membrane high affinity transporter of monocarboxylic acids such as lactate, pyruvate or acetate [46], and monocarboxylic acids can compete with selenite for entrance into the yeast cell [45]. Glucose represses expression of JEN1 [47], and induces endocytosis and ubiquitin-mediated degradation of the Jen1 protein [48]. Thus, the Jen1 transporter would not operate in glucose medium where the above mentioned phosphate transporters would be the mediators of selenite uptake. The efficient adventitious transport of selenite by Jen 1 in conditions where a carbon source alternative to glucose is employed by the yeast cells would explain why selenite toxicity is increased in respiratory growth conditions $[49,50]$.

In summary, selenite opportunistically employs mechanisms involved in transport and metabolic conversion of essential nutrients in order to enter into yeast cells. Interestingly, overexpression of the SSU1 gene (encoding for a plasma membrane sulfite pump which acts as a sulfite detoxifier in yeast cells [51]) also confers selenite tolerance [52], indicating the existence of common export mechanisms for sulfite and selenite.

\section{MECHANISMS OF Se TOXICITY IN YEAST CELLS}

Selenite and selenide cause the death of $S$. cerevisiae cells in a dose-dependent manner [52-54]. In contrast, equivalent concentrations of organic forms of Se (selenocysteine or selenomethionine) do not provoke lethality [53], although some inhibitory effects on cell growth may occur, at least in the case of selenomethionine $[29,55]$. Selenate is also toxic for yeast cells, although considerably less than selenite when equivalent concentrations are compared for effects on cell viability, ROS production or DNA damage [56]. This could be due to less efficient uptake of selenate or only partial metabolic conversion to selenite and selenide. Cells lacking the Met3 ATP sulfurylase activity are resistant to high selenate concentrations [57], yet the question if its resistance is due to impaired selenate to selenite conversion or a consequence of a repression/inhibition of sulfate transporters is still under debate [58]. It would be interesting to see if overexpression of MET3 or genes coding for related enzymatic activities may be a tool to further dissect the contribution of selenate uptake or its intracellular metabolic conversion to selenate toxicity.

\section{Genotoxic effects}

Toxicity of the inorganic Se forms results from different physiological effects that are interrelated. Selenite-treated yeast cells are prone to DNA double strand break (DSB) formation and show increased mutation rates [52, 53]. DSBs may result from the chemical alteration of DNA bases by selenite-mediated ROS that challenge replication fork integrity and genome stability in proliferating cells. However, although at lower levels, selenite also provokes DSB formation in stationary phase yeast cells [53], pointing to DNA replication-independent damage mediated by selenite (or its metabolic derivative selenide, see below). Selenite compounds have been shown to induce apoptotic death of tumor cells involving topoisomerase II (Top II) [59, 60]. Top II action involves the cleavage of both DNA strands [61] and selenite stabilizes reversible Topll cleavage complexes in vitro, suggesting that the stimulation of Top II action may be a main source of selenite-mediated DNA breaks. Selenide also breaks DNA phosphodiester bonds in vitro 
under aerobic conditions, due to the action of ROS different from $\mathrm{O} 2 \bullet-$, and similar effects may be caused by selenite provided that GSH is present in the reaction mixture [55].

In yeast cells DNA DSBs are mainly repaired by the homologous recombination (HR) pathway, taking advantage of sister chromatids as DNA repair templates [62]. In accordance, a genome-wide analysis of selenite sensitive mutants in haploid S. cerevisiae cells has revealed that HR mutants are selenite-hypersensitive [63], confirming previous results on the importance of $H R$ in protecting yeast cells against selenite-induced DNA damage [52, 64]. In addition to HR, Rad5/Rad6-mediated post-replicative repair (PRR) is required to protect cells from selenite-mediated DNA damage $[61,65]$. Although HR and PRR seem to have a synergistic effect in repairing selenite-mediated DNA damage, exposure to selenite does not stimulate the expression of DNA repair genes $[63,66]$. Notably, despite the role of non-homologous end-joining (NHEJ) in the repair of DNA DSBs [67], mutants impeded in NHEJ were dispensable for tolerance to selenite-mediated DNA damage [68]. NHEJ is the markedly preferred option for the repair of DNA lesions formed outside of the $S / G 2$ phase of the cell cycle [69], suggesting a predominant impact of selenite on the genome stability of replicating and/or dividing cells.

A recent study by Peyroche et al. revealed that selenide treatment causes oxygen-dependent DNA phosphodiesterbond breaks in vitro, and chromosome fragmentation in vivo [54]. The same study included a genome-wide screen to identify mutants that confer selenide hypersensitivity. Apparently, the repair of selenide-mediated lesions depends on HR, suggesting an overlap in the kind of DNA lesions generated by selenide and selenite. Based on these observations, it is conceivable that cells reduce selenite to selenide in the presence of oxygen thereby promoting ROS and DNA damage formation [54].

Despite the advance in our knowledge on the mechanisms that contribute to the formation and repair of Semediated DNA damage, little is known on the possible impact of Se on proteins involved in DNA metabolism. It will be interesting to see if Se compounds interfere with disulfide bridge formation and protein folding, or the function of metalloproteins such as DNA polymerases [70].

\section{Alteration of mitochondrial functions}

Mitochondria play an important role in cellular energy supply and apoptosis in yeast and higher eukaryotes [71, 72]. Mitochondrial functions are highly conserved from yeast to human, and yeast-based assays have been employed to identify drugs active against human mitochondrial disorders [73]. The intermembrane space of mitochondria contains several pro-apoptotic proteins, including cytochrome c, procaspases 2, 3, and 9, and apoptosisinducing factor, all of which are released into the cytosol as a result either of disruption of the outer mitochondrial membrane or of the opening of specific pores [74]. The opening of the mitochondrial permeability transition (MPT) pore induced by apoptotic stimuli is thus thought to result in the swelling of the mitochondrial matrix and consequent rupture of the outer membrane and release of proapoptotic proteins. MPT pore opening is regulated by $\mathrm{Ca}^{2+}$, thiol oxidants, ROS, and members of the Bcl-2 family of proteins [75-78]. S. cerevisiae has been very useful to dissect the underlying mechanisms that contribute to apoptosis but little is known on the impact of Se on yeast mitochondrial function. In human cells, apoptotic events that are mediated by selenite, selenocystine, and selenodioxide are related to oxidation of protein thiol groups and ROS generation [79]. In addition, selenite has been found to promote transitions in mitochondrial permeability, and cytochrome c release in isolated mitochondria [80]. However, enhanced Se uptake has also been shown to improve mitochondrial function, most likely because 3 out of 25 mammalian selenoproteins (TR2, GPX4 and SelO) were shown to reside in mitochondria. These proteins function in the regulation of mitochondrial redox homeostasis and antioxidant activity [81-83]. Despite the fact that $S$. cerevisae is lacking mitochondrial selenoproteins, toxic Se may as well induce apoptotic events in yeast [50]. Se and mitochondrial DNA are not essential for $S$. cerevisae growth [84], thus it was possible to identify yeast genes involved in mitochondrial function that affect intracellular Se levels [85]. It remains to be explored as to whether mutations in human genes related to mitochondrial function will affect mitochondrial Se levels, or be relevant in disease formation.

\section{Effects on the cellular redox state}

Once inside the cell selenite would employ the sulfate assimilation pathway for its conversion into the more toxic form selenide [86]. In fact, a genome-wide screen for $S$. cerevisiae mutants displaying selenite tolerance revealed that the mutants in genes involved in the conversion of sulfate into sulfur were tolerant to selenite and also to tellurite, supporting an opportunistic common assimilation pathway for both toxic oxyanions [86]. The sulfur (or selenite) assimilation pathway involves a sequence of redox reactions [87]. In the case of selenite, the above study also demonstrated that intracellular selenite reduction is linked to GSH metabolism, as a gsh2 $\Delta$ mutant defective in GSH biosynthesis is also unable to accumulate elemental selenium [86], although this does not result in increased tolerance to selenite $[63,86]$. The involvement of GSH in selenite reduction has also been initially shown in bacteria [88]. In yeast, the GIr1 glutathione reductase is the enzyme involved in maintaining most of the glutathione intracellular pool in a reduced state. This tripeptide molecule is the main intracellular redox buffer, as it is needed for the activity of redoxins, peroxidases and metal-detoxifying enzymes among others, besides forming reversible disulfide bonds with protein thiols to protect them against irreversible oxidation [89]. Selenite causes a decrease of the GSH/GSSG ratio in the cell, in addition to reduction of total glutathione $[28,90,91]$. Accordingly, overexpression of GLR1 partially rescues the inhibitory effect of selenite on yeast cell growth [52], while a glr1 $\Delta$ mutant is hypersensitive to selenite, as well as a gsh1 $\Delta$ mutant involved in the first step of GSH biosynthesis [63]. The glr1 $\Delta$ and gsh1 $\Delta$ mutants have 
also been described as hypersensitive to sodium selenide [54], again pointing to common toxicity effects between both inorganic forms of Se. A drop in intracellular GSH levels should constrain the activity of GSH-dependent ROSdetoxifying enzymes, and thus lead to ROS accumulation and macromolecular damage. Accumulation of intracellular hydrogen peroxide upon selenite treatment has been reported [49], and in addition to the above described genotoxic effects, selenite also provokes irreversible ROSmediated carbonylation of protein side chains [50]. A metabolomics study has shown that the drop in intracellular GSH levels is much lower in selenate-treated cells than in selenite-treated ones [28], which could contribute to the lower toxicity of selenate.

The observed drop in the intracellular glutathione pool upon selenite treatment cannot be simply explained by the reduction of the cytosolic GSH pool due to reduction of selenite to selenide and ROS. Detoxification of heavy atoms such as cadmium, arsenic or mercury in yeast involves the participation of the vacuolar membrane located $A B C$ transporter Ycf1 [44, 92]. Ycf1 internalizes GSH-heavy metal conjugates into the vacuolar lumen, therefore conferring heavy metal tolerance and thus, the $y c f 1 \Delta$ mutant is hypersensitive to heavy metals. On the contrary, the $y c f 1 \Delta$ mutant is resistant to selenite, while overexpression of Ycf1 exacerbates selenite toxicity [90], indicating a more complex function of the Ycf1 pump in selenite tolerance. Ycf1 is able to transport GSSG and selenodiglutathione (GSSeSG) [90]. This finding led to the proposal of a vicious cycle of selenite-mediated cytosolic GSH depletion, based on a continuous Ycf1-dependent vacuolar internalization of GSSG and GSSeSG. In the vacuole, GSSeSG converts to GSSG and selenide. In this case, selenide would again diffuse to the cytosol, while GSSG would be retained in the vacuole causing cytosolic glutathione depletion. Such scenario explains how vacuolar internalization of Se compounds alters the intracellular redox state. However, the functional integrity of vacuoles is also essential to cope with Se toxicity [63], as it will be discussed below.

Transcriptome analysis of selenide- and selenitetreated S. cerevisiae cells revealed the induction of genes participating in the oxidative stress response $[54,63,65]$ that are expressed under control of the AP-1 family like Yap1 transcription factor [93]. Genes that were upregulated by selenite included thioredoxin reductase (TTR1) and glutathione reductase (GLR1), both coding for activities required for functional (NADPH-dependent) thioredoxin and (glutathione-dependent) glutaredoxin systems, respectively. These two systems control the redox state of protein thiol groups through their thiol oxidoreductase activity and consequently, are important for repairing oxidation of these thiol groups and for protein redox modulation [94, 95]. Selenite also induces expression of peroxidases, the cytosolic catalase and $\mathrm{Cu} / \mathrm{Zn}$-dependent superoxide dismutase SOD1 [66]. Because these enzymes are involved in ROS detoxification, these observations reinforce the idea that the selenite/selenide treatment of the yeast cells causes alterations in the intracellular redox state.
The alteration of the GSH/GSSG ratio by selenite may result in general oxidation of protein thiol groups. This would explain the reported protection of dithiol glutaredoxins Grx1 and Grx2 against selenite toxicity $[49,50]$. In fact, Grx1 and Grx2 have a defense function against oxidative stress in S. cerevisiae [96], although the biochemical bases of such differential protection are not characterized. A double $g r x 1 \Delta$ grx $2 \Delta$ mutant is hypersensitive to selenite $[49,50]$, while the respective single mutants are not, which would support overlapping roles for both glutaredoxins during selenite stress [50]. Another study, however, has attributed a more important role to Grx1 in such protection, relating it to the predominant participation of superoxide in selenite-generated oxidative stress [63]. The grx1 $\Delta$ mutant has also been described as selenide-hypersensitive [54]. All these studies commonly point to the importance of yeast dithiol glutaredoxins in protection against selenite and selenide, probably through regulation of protein thiol oxidation. The reported peroxidase activity of those glutaredoxins [97] might as well contribute to such protection.

\section{SIGNALING PATHWAYS FOR Se STRESS}

Diverse stress response pathways sense the lesions caused by Se compounds in yeast cells and induce protective responses. Given the diversity of the toxic effects triggered by selenite or selenide, it is not surprising that several response transducers and effectors may be acting in parallel. Disruption of the pathways or effector loss of function results in hypersensitivity to Se molecules.

\section{The DNA damage checkpoint pathway}

Upon DNA damage, cell cycle arrest by G1/S, S and G2/M cell cycle checkpoints is essential to avoid unscheduled repair of DNA lesions [98]. In yeast, Rad9 is a central mediator of checkpoint activation throughout the cell cycle [99]. DNA lesions induce cyclin-dependent kinase or Mec1 mediated Rad9 phosphorylation and subsequent activation of signal transducers such as Rad53, which itself phosphorylates diverse downstream effectors [100-102]. In addition, Mec1 accumulation at stalled replication forks activates Mrc1, a replication fork component needed to upregulate Rad53 phosphorylation [103]. Therefore, several phosphorylation events could act in parallel to promote the activation of DNA damage response mediator proteins. Mutants in RAD9 and other genes of the pathway are hypersensitive to DNA damage mediated by UV light, DNA alkylating agents or selenite [54, 99]. Because selenite treatment causes cells to arrest at G2/M [52], Rad9dependent activation of the DNA damage checkpoint pathway seems to be important for the selenite-dependent cell cycle arrest. Furthermore, checkpoint mutants with a specific function in different stages of cell cycle are hypersensitive to selenite $[52,65]$, suggesting that selenite causes DNA damage throughout the cell cycle. In contrast, mutants in RAD9 and other genes coding for central components of the DNA damage response are not hypersensitive to selenomethionine [65]. It is therefore unlikely that this 
organic form of Se contributes to Se-mediated genotoxicity [56].

\section{The Snf1 kinase pathway in response to oxidative stress} Yeast Snf1 was identified as having a general role in the oxidative stress response and selenite tolerance [91]. Snf1 is a yeast member of the AMP-activated protein kinase (AMPK) family constituted by protein complexes that participate in metabolic stress responses responsible for the maintenance of cellular ATP levels in eukaryotes. Thus, Snf1 plays a key role in the adaptation of yeast cells to glucose limitation and the usage of alternative carbon sources [104]. To carry out this function, upstream acting protein kinases (Sak1, Elm1 or Tos1) sense the carbon source stress conditions, phosphorylate Snf1 (with Sak1 being the major player in the response to glucose scarcity) and promote its internalization to the nucleus to activate several transcription regulator targets acting as effectors of this kinase. More recently, it has been demonstrated that Snf1 does not only regulate nuclear targets, but also can modulate the function of cytosolic proteins, such as the arrestinrelated protein Rod1, which coordinates endocytosis of alternative carbon source transporters in response to glucose presence in the medium [105]. The work of PérezSampietro et al. [91] demonstrated that Elm1-dependent activation of Snf1 is required for protection against oxidants (among them selenite) causing alteration of glutathione redox homeostasis towards a more oxidized state. This protection does not require the nuclear targets of Snf1 operating during the glucose depletion response, overall defining a previously uncharacterized response against oxidative stress conditions with the participation of the Snf1 kinase. Similarly, Snf1 activity is required for cadmium tolerance independent of its nuclear targets [92]. Interestingly, in human cell lines, hydrogen peroxide activates AMPK as part of a protective signaling mechanism mediated by mTORC1 [106]. In another study on human colon cancer cells, selenate provoked a late activation of AMPK through ROS formation, and this AMPK activation was essential to inhibit cell proliferation by downregulating the COX2-mediated pathway [107]. An additional work with human cell lines also demonstrated activation of AMPK by redox changes in the $\alpha$ and $\beta$ subunits of the AMPK complex induced by hydrogen peroxide [108]. In summary, there is experimental evidence from a diversity of cell types supporting the involvement of AMPK in the response to stress by redox-altering agents, including Se compounds.

\section{The Rim101-mediated pathway and vacuolar functions}

Rim101 is a member of the fungal PacC family of $\mathrm{C}_{2} \mathrm{H}_{2}$ zinc finger transcriptional regulators that was initially characterized as modulator of the response of yeast cells to alkaline $\mathrm{pH}$. Later studies showed its implication in processes such as sporulation and invasive growth, protection against $\mathrm{Na}^{+}$and $\mathrm{Li}^{+}$toxicity, cell wall assembly, protection against weak organic acids and regulation of calcium homeostasis [109-112]. A recent study [113] has extended the range of cell processes regulated by Rim101 to vacuolar functions.
In this process Rim101 would act cooperatively with the ESCRT complex, a protein complex that was originally identified as being important for the sorting of ubiquitinated endosomal membrane proteins into the multivesicular body (MVB) [114, 115]. Further studies demonstrated additional roles of the ESCRT machinery in other cellular processes $[114,115]$, including the Rim101 signaling pathway in yeast $[110,111]$. In the absence of Rim101, expression of several VMA genes implicated in the synthesis of subunits of the vacuolar $\mathrm{H}^{+}$-ATPase (V-ATPase) complex becomes downregulated, providing a rationale for the selenite hypersensitivity of the rim101 $\Delta$ mutant [113]. On the contrary, constitutive activation of Rim101 prevents inhibition of vacuolar acidification caused by selenite. V-ATPase activity is required to maintain the acidity of the vacuolar lumen necessary for importing a number of different molecules into the vacuole, including the toxic ones [116]. These observations, together with the fact that mutants in the genes encoding the different V-ATPase subunits are hypersensitive to selenite [63], point to a scenario in which Rim101 modulates the vacuolar acidity necessary for selenite detoxification through its transcriptional activity. In this scenario, the ESCRT machinery would participate in maintenance of vacuolar acidity through both Rim101dependent and -independent pathways. Consistently with this, ESCRT mutants are also hypersensitive to selenite [113].

\section{CONCLUSIONS AND PERSPECTIVES}

The mechanisms by which Se compounds enter into $S$. cerevisiae cells and interfere with cellular processes are summarized in Fig. 2, which also depicts the activation of pathways required for Se tolerance and detoxification. Entrance of selenate and selenite (the two more abundant free forms of Se in nature) occurs through oxyanions transporters, and once in the cell they are transformed into selenide through a reductive pathway that may involve GSH. In the presence of oxygen, selenide can promote the formation of superoxide and other ROS species, which may damage DNA, proteins and probably also other cellular macromolecules. Thus, changes in the redox buffering of the cell and ROS overproduction, which themselves are two interrelated processes, would be an origin of Se toxicity.

However, many questions remain. Selenite has been shown to activate expression of genes under transcriptional control of the Aft1 regulon [66]. Genes affected encode for proteins required for the high-affinity uptake of iron and redistribution of internal iron stores under iron scarcity $[117,118]$. In addition, cells lacking Aft1 are moderately hypersensitive to selenite, this phenotype being rescued by iron supplementation to the growth medium [113]. These observations may indicate that selenite (or selenide) would interfere with iron bioavailability, the Aft1-mediated response being required in such conditions. A study has addressed the ability of selenide to form insoluble complexes in vitro with different metal anions, confirming in fact its 


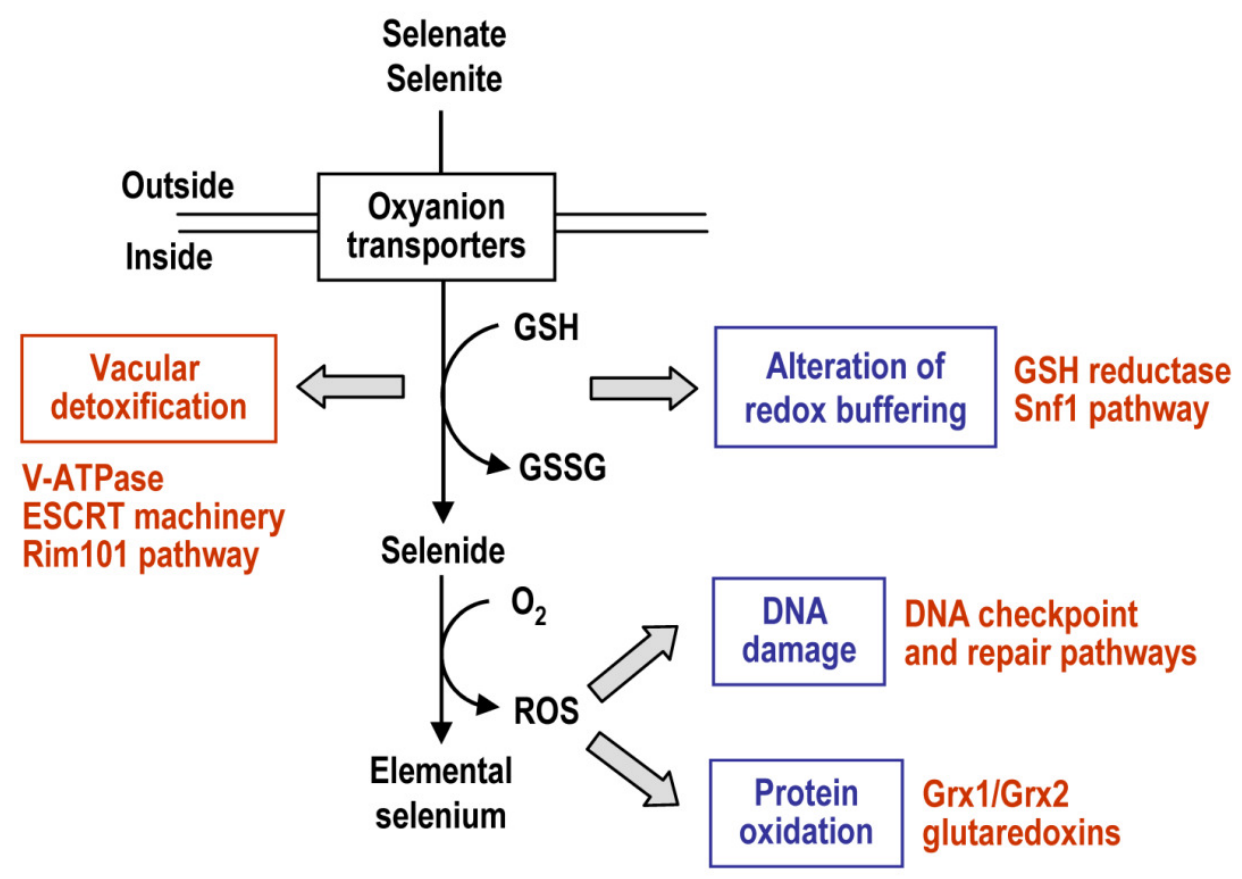

FIGURE 2: Description of factors and pathways involved in the uptake, intracellular selenium tolerance and detoxification in S. cerevisiae. See the text for details. Toxic consequences (blue) and protective mechanisms (red) are indicated.

interaction with ferrous iron and that the selenide- iron complexes become biologically inactive [119]. The possibil ity that in vivo interference can be extended to other anions is open. In addition, yeast as model organism offers the possibility to address the identification of hot spots of Semediated DNA damage, or to extend our knowledge on factors involved in signaling and repair of Se-mediated damage. It will be interesting to determine which proteins are prone to selenite or selenide-dependent modifications, including irreversible (i.e. carbonylation) or reversible (phosphorylation, ubiquitination, sumolyation) protein modifications. Finally, yeast may serve as an excellent tool for the characterization of events related to Se-mediated aging and apoptosis. Such studies are important for a better understanding of the molecular mechanism underlying Se-mediated pathologies in multicellular organisms, including humans.

\section{ACKNOWLEDGMENTS}

We thank H. Gaillard for critical reading of the manuscript. This work was supported by grants from the Universitat de Lleida to E.H. and from the Junta de Andalucía [P11-CTS7962]/European Union (FEDER) to R.E.W.

\section{CONFLICT OF INTEREST}

The authors declare no conflict of interest.

\section{COPYRIGHT}

(C) 2015 Herrero and Wellinger. This is an open-access article released under the terms of the Creative Commons Attribution (CC BY) license, which allows the unrestricted use, distribution, and reproduction in any medium, provided the original author and source are acknowledged.

Please cite this article as: Enrique Herrero and Ralf Erik Wellinger (2015). Yeast as a model system to study metabolic impact of selenium compounds. Microbial Cell 2(5): 139-149. doi: 10.15698/mic2015.05.200

2. Hawkes WC, Richter BD, Alkan Z, Souza EC, Derricote M, Mackey BE, and Bonnel EL (2008). Response of selenium status indicators to supplementation of healthy North American men with high-selenium yeast. Biol Trace Elem Res 122(2): 107-121. 
3. Kryukov GV, Castellano S, Novoselov SV, Lobanov AV, Zehtab O, Guigó R, and Gladyshev VN (2003). Characterization of mammalian selenoproteomes. Science 300(5624):1439-1443.

4. Sandalova T, Zhong L, Lindqvist $Y$, Holmgren A, and Schneider G (2001). Three-dimensional structure of a mammalian thioredoxin reductase: implications for mechanism and evolution of a selenocysteine-dependent enzyme. Proc Natl Acad Sci USA 98(17): 9533-9538.

5. Salonen JT, Alfthan G, Huttunen JK, and Puska P (1984). Association between serum selenium and the risk of cancer. Am J Epidemiol 120(3): 342-349.

6. Duffield-Lillico AJ, Dalkin BL, Reid ME, Turnbull BW, Slate EH, Jacobs ET, Marshall JR, Clark LC, and Nutritional Prevention of Cancer Study Group (2003). Selenium supplementation, baseline plasma selenium status and incidence of prostate cancer: an analysis of the complete treatment period of the Nutritional Prevention of Cancer Trial. BJU Int 91(7): 608-612.

7. Lippman SM, Klein EA, Goodman PJ, Lucia MS, Thompson IM, Ford LG, Parnes HL, Minasian LM, Gaziano JM, Hartline JA, Parsons JK, Bearden JD 3rd, Crawford ED, Goodman GE, Claudio J, Winquist E, Cook ED, Karp DD, Walther P, Lieber MM, Kristal AR, Darke AK, Arnold KB, Ganz PA, Santella RM, Albanes D, Taylor PR, Probstfield JL, Jagpal TJ, Crowley JJ, Meyskens FL Jr, Baker LH, and Coltman CA Jr (2009). Effect of selenium and vitamin $\mathrm{E}$ on risk of prostate cancer and other cancers: the Selenium and Vitamin E Cancer Prevention Trial (SELECT). JAMA 301(1): 39-51.

8. Klein EA, Thompson IM Jr, Tangen CM, Crowley JJ, Lucia MS, Goodman PJ, Minasian LM, Ford LG, Parnes HL, Gaziano JM, Karp DD, Lieber MM, Walther PJ, Klotz L, Parsons JK, Chin JL, Darke AK, Lippman SM, Goodman GE, Meyskens FL Jr, and Baker LH (2011). Vitamin E and the risk of prostate cancer: the Selenium and Vitamin E Cancer Prevention Trial (SELECT). JAMA 306(14): 1549-1556.

9. Kristal AR, Darke AK, Morris JS, Tangen CM, Goodman PJ, Thompson IM, Meyskens FL Jr, Goodman GE, Minasian LM, Parnes HL, Lippman SM, and Klein EA (2014). Baseline selenium status and effects of selenium and vitamin e supplementation on prostate cancer risk. J Natl Cancer Inst 106(3): djt456.

10. Salonen JT, Alfthan G, Huttunen JK, Pikkarainen J, and Puska P (1982) Association between cardiovascular death and myocardial infarction and serum selenium in a matched-pair longitudinal study. Lancet 2(8291): 175-179.

11. Kilness AW, and Hichberg FH (1977). Amyotrophic lateral sclerosis in a high selenium environment. JAMA 237(26): 2843-2844.

12. Norris FH Jr, and U KS (1978). Amyotrophic lateral sclerosis and low urinary selenium levels. JAMA 239(5): 404.

13. Tan $M$, Sheng $L$, Qian $Y$, Ge $Y$, Wang $Y$, Zhang $H$, Jiang $M$, and Zhang $G$ (2001). Changes of serum selenium in pregnant women with gestational diabetes mellitus. Biol Trace Elem Res 83(3): 231-237.

14. Brozmanová J, Mániková D, Vlcková V, and Chovanec M (2010). Selenium: a double-edged sword for defense and offence in cancer. Arch Toxicol 84(12): 919-938.

15. Stadtman TC (1996). Selenocysteine. Annu Rev Biochem 65:83100 .

16. Jiang L, Ni J, and Liu Q (2012). Evolution of selenoproteins in the metazoan. BMC Genomics 13: 446.

17. Stolz JF, and Oremland RS (1999). Bacterial respiration of arsenic and selenium. FEMS Microbiol Rev 23(5): 615-627.
18. Macy JM, Rech S, Auling G, Dorsch M, Stackebrandt E, and Sly LI (1993). Thauera selenatis gen. nov., sp. nov., a member of the beta subclass of Proteobacteria with a novel type of anaerobic respiration. Int J Syst Bacteriol 43(1): 135-142.

19. Debieux CM, Dridge EJ, Mueller CM, Splatt $P$, Paszkiewicz K, Knight I, Florance H, Love J, Titball RW, Lewis RJ, Richardson DJ, and Butler CS. (2011). A bacterial process for selenium nanosphere assembly. Proc Natl Acad Sci USA 108(33): 13480-13485.

20. Oremland RS, Hollibaugh JT, Maest AS, Presser TS, Miller LG, and Culbertson CW (1989). Selenate reduction to elemental selenium by anaerobic bacteria in sediments and culture: biogeochemical significance of a novel, sulfate-independent respiration. Appl Environ Microbiol 55(9): 2333-2343.

21. Cutter GA (1982). Selenium in reducing waters. Science 217(4562): 829-831.

22. Stork A, Jury WA, and Frankenberger WT Jr (1999). Accelerated volatilization rates of selenium from different soils. Biol Trace Elem Res 69(3): 217-234.

23. Zhang L, Li D, and Gao P (2012). Expulsion of selenium/protein nanoparticles through vesicle-like structures by Saccharomyces cerevisiae under microaerophilic environment. World J Microbiol Biotechnol 28(12): 3381-3386.

24. Oremland RS, Hoeft SE, Santini JM, Bano N, Hollibaugh RA, and Hollibaugh JT (2002). Anaerobic oxidation of arsenite in Mono Lake water and by a facultative, arsenite-oxidizing chemoautotroph, strain MLHE-1. Appl Environ Microbiol 68(10): 4795-4802.

25. Spallholz JE (1997). Free radical generation by selenium compounds and their prooxidant toxicity. Biomed Environ Sci 10(2-3): 260-270.

26. Letavayová L, Vicková V, and Brozmanová J (2006). Selenium: from cancer prevention to DNA damage. Toxicology 227(1-2): 1-14.

27. Sun HJ, Rathinasabapathi B, Wu B, Luo J, Pu LP, and Ma LQ (2014). Arsenic and selenium toxicity and their interactive effects in humans. Environ Int 69: 148-158.

28. Rao Y, McCooeye M, Windust A, Bramanti E, D'Ulivo A, and Mester Z (2010). Mapping of selenium metabolic pathway in yeast by liquid chromatography-orbitrap mass spectrometry. Anal Chem 82(19): 8121-8130.

29. Kitajima T, Jigami $Y$, and Chiba $Y$ (2012). Cytotoxic mechanism of selenomethionine in yeast. J Biol Chem 287(13): 10032-10038.

30. Arnaudguilhem C, Bierla K, Ouerdane L, Preud'homme H, Yiannikouris A, and Lobinski $R$ (2012). Selenium metabolomics in yeast using complementary reversed-phase/hydrophilic ion interaction (HILIC) liquid chromatography-electrospray hybrid quadrupole trap/Orbitrap mass spectrometry. Anal Chem Acta 752: 26-38.

31. Cherest H, Davidian JC, Thomas D, Benes V, Ansorge W, and Surdin-Kerjan $Y$ (1997). Molecular characterization of two high affinity sulfate transporters in Saccharomyces cerevisiae. Genetics 145(3): 627-635.

32. Pereira $Y$, Lagniel G, Godat E, Baudouin-Cornu $P$, Junot $C$, and Labarre J (2008). Chromate causes sulfur starvation in yeast. Toxicol Sci 106(2): 400-412.

33. Fitzpatrick KL, Tyerman SD, and Kaiser BN (2008). Molybdate transport through the plant sulfate transporter SHST1. FEBS Lett 582(10): 1508-1513.

34. Gharieb MM, and Gadd GM (2004). The kinetics of [75Se] uptake by Saccharomyces cerevisiae and the vacuolization response to high concentrations. Mycol Res 108(12): 1415-1422. 
35. Pinson B, Merle M, Franconi JM, and Daignan-Fornier B (2004). Low affinity orthophosphate carriers regulate $\mathrm{PHO}$ gene expression independently of internal orthoposphate concetration in Saccharomyces cerevisiae. J Biol Chem 279(34): 35273-35280.

36. Tarze A, Dauplais M, Grigoras I, Lazard M, Ha-Duong NT, Barbier F, Blanquet $S$, and Plateau $P$ (2007). Extracellular production of hydrogen selenide accounts for thiol-assisted toxicity of selenite against Saccharomyces cerevisiae. J Biol Chem 282(12): 8759-8767.

37. Lazard M, Blanquet S, Fisicaro P, Labarraque G, and Plateau P (2010). Uptake of selenite by Saccharomyces cerevisiae involves the high and low affinity orthophosphate transporters. J Biol Chem 285(42): 32029-32037

38. Persson BL, Lagerstedt JO, Pratt JR, Pattison-Granberg J, Lundh K Shokrollahzadeh S, and Lundh F (2003). Regulation of phosphate acquisition in Saccharomyces cerevisiae. Curr Genet 43(4): 225-244.

39. Mouillon JM, and Persson BL (2006). New aspects on phosphate sensing and signalling in Saccharomyces cerevisiae. FEMS Yeast Res 6(2): 171-176

40. Huang D, Friesen $H$, and Andrews B (2007). Pho85, a multifunctional cyclin-dependent protein kinase in budding yeast. Mol Microbiol 66(2): 303-314

41. Zvyagilskaya RA, Lundh F, Samyn D, Pattison-Granberg I, Mouillon JM, Popova Y, Thevelein JM, and Persson BL (2008). Characterization of the Pho89 phosphate transporter by functional hyperexpression in Saccharomyces cerevisiae. FEMS Yeast Res 8(5): 685-696.

42. Bun-ya M, Harashima $S$, and Oshima $Y$ (1992). Putative GTPbinding protein, Gtr1, associated with the function of the Pho84 inorganic phosphate transporter in Saccharomyces cerevisiae. Mol Cell Biol 12(7): 2958-2966.

43. Jensen LT, Ajua-Alemanji M, and Culotta VC (2003). The Saccharomyces cerevisiae high affinity phosphate transporter encoded by $\mathrm{PHO} 84$ also functions in manganese homeostasis. J Biol Chem 278(43): 42036-42040.

44. Wysocki R, and Tamás MJ (2010). How Saccharomyces cerevisiae copes with toxic metals and metalloids. FEMS Microbiol Rev 34(6): 925-951.

45. McDermott JR, Rosen BP, and Liu Z (2010). Jen1p: a high affinity selenite transporter in yeast. Mol Biol Cell 21(22): 3934-3941.

46. Casal M, Paiva S, Queiros O, and Soares-Silva I (2008). Transport of carboxylic acids in yeasts. FEMS Microbiol Rev 32(6): 974-994.

47. Chambers P, Isaka A, and Palecek SP (2004). Saccharomyces cerevisiae JEN1 promoter activity is inversely related to concentration of repressing sugar. Appl Environ Microbiol 70(1): 8-17.

48. Paiva S, Vieira N, Nondier I, Haguenauer-Tsapis R; Casal M, and Urban-Grimal D (2009). Glucose-induced ubiquitination and endocytosis of the yeast Jen1 transporter: role of lysine 63-linked ubiquitin chains. J Biol Chem 284(29): 19228-19236.

49. Lewinska A, and Bartosz G (2008). A role for yeast glutaredoxin genes in selenite-mediated oxidative stress. Fungal Genet Biol 45(8): 1182-1187.

50. Izquierdo A, Casas C, and Herrero E (2010). Selenite-induced cell death in Saccharomyces cerevisiae: protective role of glutaredoxins. Microbiology 156(9): 2608-2620.

51. Park H, and Bakalinsky AT (2000). SSU1 mediates sulphite efflux in Saccharomyces cerevisiae. Yeast 16(10): 881-888.

52. Pinson B, Sagot I, and Daignan-Fornier B (2000). Identification of genes affecting selenite toxicity and resistance in Saccharomyces cerevisiae. Mol Microbiol 36(3): 679-687.
53. Letavayová L, Vlasákova D, Spallholz JE, Brozmanová J, and Chovanec M (2008). Toxicity and mutagenicity of selenium compounds in Saccharomyces cerevisiae. Mutat Res 638(1-2): 1-10.

54. Peyroche G, Saveanu C, Dauplais M, Lazard M, Beuneu F, Decourty L, Malabat C, Jacquier A, Blanquet S, and Plateau P (2012). Sodium selenide toxicity is mediated by O2-dependent DNA breaks. PLoS One 7(5): e36343.

55. Bockhorn J, Balar B, He D, Seitomer E, Copeland PR, and Kinzy TG (2008). Genome-wide screen of Saccharomyces cerevisiae null allele strains identifies genes involved in selenomethionine resistance. Proc Natl Acad Sci USA 105(46): 17682-17687.

56. Mániková $D$, Letavayová $L M$, Vlasáková $D$, Košík $P$, Estevam EC, Nasim MJ, Gruhlke M, Slusarenko A, Burkholz T, Jacob $C$, and Chovanec M (2014). Intracellular diagnostics: hunting for the mode of action of redox-modulating selenium compounds in selected model systems. Molecules 19(8): 12258-12279.

57. Breton A, and Surdin-Kerjan $Y$ (1977). Sulfate uptake in Saccharomyces cerevisiae: biochemical and genetic study. J Bacteriol 132(1): 224-232.

58. Tamás MJ, Labarre J, Toledano MB, and Wysocki R (2005). Mechanisms of toxic metal tolerance in yeast. In: Tamás MJ, Martincia $E$, editors. Biology of metal homeostasis and detoxification. SpringerVerlag, Heidelberg; pp 395-454.

59. Zhou N, Xiao H, Li TK, Nur EKA, and Liu LF (2003). DNA damagemediated apoptosis induced by selenium compounds. J Biol Chem 278(32): 29532-29537.

60. López-Lázaro M, Willmore E, Elliott SL, and Austin CA (2008). Selenite induces topoisomerase I and II-DNA complexes in K562 leukemia cells. Int J Cancer 123(9): 2217-2221.

61. Roca J, and Wang JC (1992). The capture of a DNA double helix by an ATP-dependent protein clamp: a key step in DNA transport by type II DNA topoisomerases. Cell 71(5): 833-840.

62. Krejcí L, Altamannova V, Spirek M, and Zhao X (2012). Homologous recombination and its regulation. Nucleic Acids Res 40(13): 5795-5818.

63. Mániková $D$, Vlasáková $D$, Letavayová $L$, Klobucniková $V$, Griac $P$, and Chovanec $M$ (2012). Selenium toxicity toward yeast as assessed by microarray analysis and deletion mutant library screen: a role for DNA repair. Chem Res Toxicol 25(8): 1598-1608.

64. Letavayová L, Vlasáková D, Vlcková V, Brozmanová J, and Chovanec M (2008). Rad52 has a role in the repair of sodium seleniteinduced DNA damage in Saccharomyces cerevisiae. Mutat Res 652(2): 198-203.

65. Seitomer E, Balar B, He D, Coperland PR, and Kinzy TG (2008). Analysis of Saccharomyces cerevisiae nul allele strains identifies a larger role for DNA damage versus oxidative stress pathways in growth inhibition by selenium. Molec Nutr Food Res 52(11): 13051315

66. Salin H, Fardeau V, Piccini E, Lelandais G, Tanty V, Lemoine S, Jacq $C$, and Devaux $F$ (2008). Structure and properties of transcriptional networks driving selenite stress response in yeasts. BMC Genomics 9: 333.

67. Chiruvella KK, Liang Z, and Wilson TE (2013). Repair of doublestrand breaks by end joining. Cold Spring Harb Perspect Biol 5(5): a012757.

68. Mániková D, Vlasáková $D$, Vlasáková $D$, Loduhová J, Letavayová L, Vigasová D, Krascsenitsová E, Vlcková V, Brozmanová J, and Chovanec $\mathrm{M}$ (2010). Investigations on the role of base excision repair and nonhomologous end-joining pathways in sodium selenite-induced toxicity and mutagenicity in Saccharomyces cerevisiae. Mutagenesis 25(2): 155-162. 
69. Lieber MR (2010). The mechanism of double-strand DNA break repair by the nonhomologous DNA end-joining pathway. Annual Rev Biochem 79: 181-211.

70. Netz DJ, Stith CM, Stümpfig M, Köpf G, Vogel D, Genau HM, Stodola JL, Lill R, Burgers PM, and Pierik AJ (2011). Eukaryotic DNA polymerases require an iron-sulfur cluster for the formation of active complexes. Nature Chem Biol 8(1): 125-132.

71. Carmona-Gutierrez D, Eisenberg T, Büttner S, Meisinger C, Kroemer G, and Madeo F. (2010). Apoptosis in yeast: triggers, pathways, subroutines. Cell Death Differ 17(5): 763-773.

72. Elmore S (2007). Apoptosis: a review of programmed cell death. Toxicol Pathol 35(4): 495-516.

73. Couplan E, Aiyar RS, Kucharczyk R, Kabala A, Ezkurdia N, Gagneur J, St Onge RP, Salin B, Soubigou F, Le Cann M, Steinmetz LM, di Rago JP, and Blondel M. (2011). A yeast-based assay identifies drugs active against human mitochondrial disorders. Proc Natl Acad Sci USA 108(29): 11989-11994.

74. Delivani P, and Martin SJ (2006). Mitochondrial membrane remodeling in apoptosis: an inside story. Cell Death Differ 13(12): 2007-2010.

75. Fagian MM, Pereira-da-Silva L, Martins IS, and Vercesi AE (1990). Membrane protein thiol cross-linking associated with the permeabilization of the inner mitochondrial membrane by $\mathrm{Ca} 2+$ plus prooxidants. J Biol Chem 265(32): 19955-19960.

76. Cai J, and Jones DP (1998). Superoxide in apoptosis. Mitochondrial generation triggered by cytochrome c loss. J Biol Chem 273(19): 11401-11404.

77. Kluck RM, Bossy-Wetzel E, Green DR, and Newmeyer DD (1997). The release of cytochrome $\mathrm{c}$ from mitochondria: a primary site for Bcl2 regulation of apoptosis. Science 275(5303): 1132-1136.

78 Yang J, Liu X, Bhalla K, Kim CN, Ibrado AM, Cai J, Peng TI, Jones DP, and Wang $X$ (1997). Prevention of apoptosis by $\mathrm{Bcl}-2$ : release of cytochrome c from mitochondria blocked. Science 275(5303): 11291132.

79. Kim TS, Yun BY, and Kim IY (2003). Induction of the mitochondrial permeability transition by selenium compounds mediated by oxidation of the protein thiol groups and generation of the superoxide. Biochem Pharmacol 66(12): 2301-2311.

80. Zhu $Y, X u H$, and Huang $K$ (2002). Mitochondrial permeability transition and cytochrome $\mathrm{c}$ release induced by selenite. J Inorg Biochem 90(1-2): 43-50.

81. Reeves MA, and Hoffmann PR (2009). The human selenoproteome: recent insights into functions and regulation. Cell Mol Life Sci 66(15): 2457-2478.

82. Turanov AA, Su D, and Gladyshev VN (2006). Characterization of alternative cytosolic forms and cellular targets of mouse mitochondrial thioredoxin reductase. J Biol Chem 281(32): 2295322963.

83. Han SJ, Lee BC, Yim SH, Gladyshev VN, and Lee SR (2014). Characterization of mammalian selenoprotein $\mathrm{o}$ : a redox-active mitochondrial protein. PloS One 9(4): e95518.

84. Chen XJ, and Clark-Walker GD (2000). The petite mutation in yeasts: 50 years on. Int Rev Cytol 194: 197-238.

85. Eide DJ, Clark S, Nair TM, Gehl M, Gribskov M, Guerinot ML, and Harper JF (2005) Characterization of the yeast ionome: a genomewide analysis of nutrient mineral and trace element homeostasis in Saccharomyces cerevisiae. Genome Biol 6(9): R77.
86. Ottosson LG, Logg K, Ibstedt S, Sunnerhagen P, Käll M, Blomberg A, and Warringer J (2010). Sulfate assimilation mediates tellurite reduction and toxicity in Saccharomyces cerevisiae. Eukaryot Cell 9(10): 1635-1647.

87. Thomas D, and Surdin-Kerjan Y (1997). Metabolism of sulfur amino acids in Saccharomyces cerevisiae. Microbiol Mol Biol Rev 61(4): 503 532.

88. Turner RJ, Weiner JH, and Taylor DE (1998). Selenium metabolism in Escherichia coli. Biometals 11(3): 223-227.

89. Deponte $M$ (2013). Glutathione catalysis and the reaction mechamisms of glutathione-dependent enzymes. Biochim Biophys Acta 1830(5): 3217-3266.

90. Lazard M, Ha-Duong NT, Mounié S, Perrin R, Plateau $P$, and Blanquet $S$ (2011). Selenodiglutathione uptake by the Saccharomyces cerevisiae vacuolar ATP-binding cassette transporter Ycf1p. FEBS J 278(21): 4112-4121.

91. Pérez-Sampietro M, Casas C, and Herrero E (2013). The AMPK family member Snf1 protects Saccharomyces cerevisiae cells upon glutathione oxidation. PLoS One 8(3): e58283.

92. Thorsen M, Perrone GG, Kristiansson E, Traini M, Ye T, Dawes IW, Nerman O, and Tamás MJ (2009). Genetic basis of arsenite and cadmium tolerance in Saccharomyces cerevisiae. BMC Genomics 10: 105.

93. Lee J, Godon C, Lagniel G, Spector D, Garin J, Labarre J, and Toledano MB (1999). Yap1 and skn7 control two specialized oxidative stress response regulons in yeast. J Biol Chem 274(23): 16040-16046.

94. Herrero E, Ros J, Bellí G, and Cabiscol E (2008). Redox control and oxidative stress in yeast cells. Biochim Biophys Acta 1780(11): 12171235.

95. Lillig $\mathrm{CH}$, and Berndt $\mathrm{C}$ (2013). Glutaredoxins in thiol/disulfide exchange. Antiox Redox Signal 18(13): 1654-1665.

96. Luikenhuis S, Perrone G, Dawes IW, and Grant CM (1998). The yeast Saccharomyces cerevisiae contains two glutaredoxin genes that are required for protection against reactive oxygen species. Mol Biol Cell 9(5): 1081-1091.

97. Collinson EJ, Wheeler GL, Garrido EO, Avery AM, Avery SV, and Grant CM. (2002). The yeast glutaredoxins are active as glutathione peroxidases. J Biol Chem 277(19): 16712-16717.

98. Weinert $T$ (1998). DNA damage checkpoints update: getting molecular. Curr Opin Genet Dev 8(2): 185-193.

99. Toh GW, and Lowndes NF (2003). Role of the Saccharomyces cerevisiae Rad9 protein in sensing and responding to DNA damage. Biochem Soc Trans 31(1): 242-246.

100. Naiki T, Wakayama T, Nakada D, Matsumoto K, and Sugimoto K (2004). Association of Rad9 with double-strand breaks through a Mec1-dependent mechanism. Mol Cell Biol 24(8): 3277-3285.

101. Wang G, Tong X, Weng S, and Zhou H (2012). Multiple phosphorylation of Rad9 by CDK is required for DNA damage checkpoint activation. Cell Cycle 11(20): 3792-3800.

102. Abreu CM, Kumar R, Hamilton D, Dawdy AW, Creavin K, Eivers S, Finn K, Balsbaugh JL, O'Connor R, Kiely PA, Shabanowitz J, Hunt DF, Grenon M, and Lowndes NF (2013). Site-specific phosphorylation of the DNA damage response mediator Rad9 by cyclin-dependent kinases regulates activation of checkpoint kinase 1. PLoS Genetics 9(4): e1003310.

103. Osborn AJ, and Elledge SJ (2003). Mrc1 is a replication fork component whose phosphorylation in response to DNA replication stress activates Rad53. Genes Dev 17(14): 1755-1767. 
104. Hedbacker K, and Carlson M (2008). SNF1/AMPK pathways in yeast. Frontiers Biosci 13: 2408-2420.

105. Becuwe M, Vieira N, Lara D, Gomes-Rezende J, Soares-Cunha C Casal M, Haguenauer-Tsapis R, Vincent O, Paiva S, and Léon S (2012). A molecular switch on an arrestin-like protein relays glucose signaling to transporter endocytosis. J Cell Biol 196(2): 247-259.

106. Alexander A, Cai SL, Kim J, Nanez A, Sahin M, MacLean KH, Inoki K, Guan KL, Shen J, Person MD, Kusewitt D, Mills GB, Kastan MB, and Walker CL (2010). ATM signals to TSC2 in the cytoplasm to regulate mTORC1 in response to ROS. Proc Natl Acad Sci USA 107(9): 41534158.

107. Hwang JT, Kim YM, Surh YJ, Baik HW, Lee SK, Ha J, and Park OJ (2006). Selenium regulates cyclooxigenase-2 and extracellular signalregulated kinase signaling pathways by activating AMP-activated protein kinase in colon cancer cells. Cancer Res 66(20): 10057-10063.

108. Zmijewski JW, Banerjee S, Bae H, Figgeri A, Lazarowski ER, and Abraham E (2010). Exposure to hydrogen peroxide induces oxidation and activation of AMP-activated protein kinase. J Biol Chem 285(43): 33154-33164.

109. Lamb TM, Xu W, Diamond A, and Mitchell AP (2001). Alkaline response genes of Saccharomyces cerevisiae and their relationship to the RIM101 pathway. J Biol Chem 276(3): 1850-1856.

110. Peñalva MA, Tilburn J, Bignell E, and Arst HN Jr (2008). Ambient $\mathrm{pH}$ gene regulation in fungi: making connections. Trends Microbiol 16(6): 291-300.
111. Maeda T (2012). The signalling mechanism of ambient $\mathrm{pH}$ sensing and adaptation in yeast and fungi. FEBS J 279(8): 1407-1413.

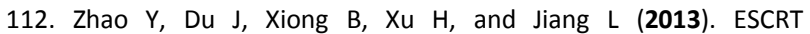
components regulate the expression of the ER/Golgi calcium pump gene PMR1 through the Rim101/Nrg1 pathway in budding yeast. J Mol Cell Biol 5(5): 336-344.

113. Pérez-Sampietro $M$, and Herrero E (2014). The PacC-family protein Rim101 prevents selenite toxicity in Saccharomyces cerevisiae by controlling vacuolar acidification. Fungal Genet Biol 71: 76-85.

114. Henne WM, Buchkovich NJ, and Emr SD (2011). The ESCRT pathway. Dev Cell 21(1): 77-91.

115. Babst M (2011). MVB vesicle formation: ESCRT-dependent, ESCRT-independent and everything in between. Curr Opin Cell Biol 23(4): 452-457.

116. Li SC, and Kane PM (2009). The yeast lysosome-like vacuole: endpoint and crossroads. Biochim Biophys Acta 1793(4): 650-663.

117. Philpott CC, and Protchenko O (2008). Response to iron deprivation in Saccharomyces cerevisiae. Eukaryot Cell 7(1): 20-27.

118. Kaplan CD, and Kaplan J (2009). Iron acquisition and transcriptional regulation. Chem Rev 109(10): 4536-4552.

119. Dauplais M, Lazard M, Blanquet S, and Plateau P. (2013). Neutralization by metal ions of the toxicity of sodium selenide. PLoS One 8(1): e54353. 